\title{
Primary biliary cirrhosis: an increased incidence of extrahepatic malignancies?
}

\author{
PR MILLS, P BOYLE, EMM QUIGLEY, GG BIRNIE, F JARRETT, \\ G WATKINSON, RNM MACSWEEN
}

\begin{abstract}
From the Gastroenterology Unit and Department of Pathology, Western Infirmary and West of Scotland Cancer Surveillance Unit, Ruchill Hospital, Glasgow
\end{abstract}

SUMMARY In a retrospective review of 85 patients with primary biliary cirrhosis (PBC), $10(11 \cdot 8 \%)$ were noted to have extrahepatic malignant neoplasm. In seven female patients the tumour developed within a mean of $3.5 \mathrm{yr}$ after the clinical onset of PBC. This observed number of tumours, 3.5 times more common than the expected age-adjusted incidence, was statistically significant at the $0.5 \%$ level.

Primary biliary cirrhosis (PBC) is a slowly progressive form of autoimmune chronic liver disease. An association between autoimmune disease states and the development of malignancy, in particular lymphoma, has been recognised for some time. ${ }^{1}$ In common with other forms of cirrhosis PBC may, albeit rarely, be complicated by primary hepatocellular carcinoma. ${ }^{2}$ However, in addition there are preliminary reports which suggest an increased incidence of extrahepatic malignancy in both PBC and chronic active hepatitis. ${ }^{34}$ In the present retrospective study we have found an increased incidence of extrahepatic malignancy in a series of patients with PBC.

\section{PATIENTS AND METHODS}

Eighty-five patients ( 9 male) with a diagnosis of PBC were reviewed. All patients had liver biopsy changes diagnostic of or consistent with $\mathrm{PBC}$ and 78 $(92 \%)$ had a positive $\mathrm{M}$-antibody at a titre $\geqslant 1 / 32$. These patients had either attended the Western Infirmary, Glasgow (44 patients) or had had serum for M-antibody or a liver biopsy for interpretation referred to the Western Infirmary from other hospitals in the West of Scotland, at some time over the period 1965 to 1979 inclusive. The case records were re-examined; all available biopsy and postmortem tissue was reviewed by two of us (RNM $\mathrm{McS}$ and $\mathrm{FJ}$ ) and a diagnosis of malignancy was accepted only if confirmed histologically.

STATISTICAL ANALYSIS

Statistical analysis was confined to the 76 female

Accepted for publication 5 October 1981 patients as the number of males was too small to obtain meaningful results. Analysis was by an agespecific person-years of risk approach, ${ }^{5}$ this being defined as the interval between the diagnosis of PBC and the following end-points: development of tumour, death with no mention of tumour or censoring (alive and tumour-free). The "expected" number of cases of tumour in these 76 patients was calculated using average annual age-specific cancer incidence rates for all sites derived from the West of Scotland Cancer Registry (1975-1977), which covers a population of three million. ${ }^{6}$ The probability of an observed value differing from the expected rate was tested using the Poisson distribution.

\section{Results}

Two of the PBC patients had a primary hepatocellular carcinoma and have already been reported in full. ${ }^{2}$ Ten patients ( 2 males) with extrahepatic malignancy were identified and the details are summarised in the Table. The mean age at the time of diagnosis of $\mathrm{PBC}$ in those with and those without malignancy was 63 and $58 \mathrm{yr}$ respectively and the mean duration of follow-up 4.6 and $5.3 \mathrm{yr}$. In patient No 6 an adenocarcinoma of the uterus, treated by hysterectomy, preceded the onset of PBC; a renal cell carcinoma was an incidental finding at necropsy. Of the eight patients with malignancy who had died at the time of review, tumour was regarded as the primary cause of death in three and the other five died in hepatic failure. In eight patients (Nos 1-8) the diagnosis of PBC preceded the development of tumour by a mean of $3.5 \mathrm{yr}$ (prospective group), while in the remaining two patients (Nos 9, 10) 
Details of PBC patients with extrahepatic malignancy

\begin{tabular}{|c|c|c|c|c|c|c|}
\hline \multirow[t]{2}{*}{ Patient } & \multirow[t]{2}{*}{ Sex } & \multicolumn{2}{|c|}{$\begin{array}{l}\text { Age at time of diagnosis } \\
(\mathrm{vr})\end{array}$} & \multirow[t]{2}{*}{$\begin{array}{l}\text { Drug* } \\
\text { history }\end{array}$} & \multirow[t]{2}{*}{ Malignancy } & \multirow[t]{2}{*}{ Cause of death } \\
\hline & & $P B C$ & Malignancy & & & \\
\hline 1 & $\mathrm{~F}$ & 63 & 66 & A $(2 \cdot 5), C$ & Carcinoma of breast & Tumour \\
\hline 2 & $\mathbf{F}$ & 49 & 52 & C & Carcinoma of breast & PBC \\
\hline 3 & $\mathbf{F}$ & 69 & 76 & Nil & Carcinoma of breast & Alive \\
\hline 4 & $\mathbf{F}$ & 62 & 65 & $A(1 \cdot 5)$ & Carcinoma of colon & PBC \\
\hline 5 & $\mathbf{M}$ & 71 & 72 & Nil & $\begin{array}{l}\text { Squamous cell carcinoma-? primary in } \\
\text { lung }\end{array}$ & Tumour \\
\hline 6 & $\mathrm{~F}$ & 56 & $\begin{array}{l}51 \\
61\end{array}$ & $A(1 \cdot 3)$ & $\begin{array}{l}\text { Adenocarcinoma uterus } \\
\text { Renal cell carcinoma } \dagger\end{array}$ & PBC \\
\hline 7 & $\mathbf{F}$ & 51 & 56 & Nil & Adenocarcinoma ovary & Tumour \\
\hline 8 & $\mathrm{~F}$ & 68 & 69 & $\mathrm{Nil}$ & Carcinoma of larynx & PBC \\
\hline 9 & $\mathrm{~F}$ & 57 & 39 & $A(4), C$ & Carcinoma of uterine cervix & Alive \\
\hline 10 & $\mathbf{M}$ & 82 & 70 & $\mathrm{Nil}$ & Carcinoma of stomach & PBC \\
\hline
\end{tabular}

* $A=$ azathioprine (yr on treatment $) ; C=$ cholestyramine. + Incidental finding at necropsy.

tumour preceded the onset of PBC by a mean of $15 \mathrm{yr}$. Seven cases of tumour were observed in the females in the prospective group compared with a calculated expected incidence of 1.99 , providing a significantly increased observed to expected ratio of 3.52 ( $p<$ 0.005).

Twenty of the 76 female patients had been included in a controlled clinical trial of azathioprine $\left(1 \mathrm{mg} / \mathrm{kg}\right.$ body weight daily) $;^{7}$ of the 10 who received the drug there were three in the present series (Nos 4, 6, 9). Patient No 1 had received azathioprine $100 \mathrm{mg}$ and prednisolone $10 \mathrm{mg}$ per day for $2.5 \mathrm{yr}$. The mean duration of treatment with azathioprine for the three patients (Nos $1,4,6)$ in the prospective group was $1.8 \mathrm{yr}$. In addition, three patients (Nos 1, 2, 9) had received cholestyramine. No statistical relation (fourfold table and Fisher's exact probability test) between the use of azathioprine and development of extrahepatic malignancy could be established.

\section{Discussion}

In this series of 85 patients with PBC, $10(11 \cdot 8 \%)$ developed an extrahepatic malignancy. When the data is analysed for the 76 female cases the observed incidence of malignancy is 3.5 times more than expected, a statistically significant finding. The most common site of malignancy was the breast (3) with single examples of a variety of other tumours; no cases of lymphoma were noted. Extrahepatic malignancy has previously been described in three $(7.7 \%)$ out of a series of 39 patients with PBC, the tumours comprising one case each of carcinoma of the breast and of the thyroid and one mixed histiolymphocytic lymphoma. ${ }^{3}$ In a retrospective review of 520 patients with cirrhosis of varying causes coming to necropsy at the Western Infirmary over the period $1900-1969,25(4.8 \%)$ were found to have extrahepatic tumours. ${ }^{8}$ On this basis it can be tentatively suggested that patients with PBC appear to be more at risk of developing extrahepatic malignancy than cirrhosis patients in general.

Three patients in our prospective group (Nos 1, 4, 6 ) had received azathioprine in low dose for a mean of $1.8 \mathrm{yr}$ and in these the primary malignancy affected breast, colon and kidney (the adenocarcinoma of uterus in case 6 antedated the use of azathioprine). In previous reviews of immunosuppressed patients the tumours found were predominantly lymphomas, and epithelial tumours of the skin, lip and cervix uteri. ${ }^{9}$ These patients had received high doses of combination immunosuppressive therapy. However, in a series of 125 Australian patients, given azathioprine for two years for a variety of medical disorders, two squamous cell carcinomas of skin only were found after a mean observation period of $3.8 \mathrm{yr} .^{10}$ In patients on chronic renal dialysis an increased incidence of non-Hodgkin's lymphoma has been reported and the immunosuppressive effect of uraemia has been postulated as a possible contributory factor. ${ }^{11}$ However, the evidence indicating that impaired immunological surveillance is a factor in promoting human carcinogenesis remains equivocal.

Vitamin A deficiency leads to metaplasia of epithelial cells in animals and an enhanced susceptibility to malignancy. ${ }^{12}$ Primary biliary cirrhosis may result in impaired absorption of fat-soluble vitamins, and in a personal series of 23 PBC patients without tumour the mean serum vitamin $\mathrm{A}$ concentration $(1.38 \mu \mathrm{mol} / \mathrm{l})$ was significantly lower than in 55 age and sex-matched controls $(1.92 \mu \mathrm{mol} / \mathrm{l})$. In the present series, however, malignancy occurred in sites different from those previously associated with low serum vitamin A concentrations, namely lung and gastrointestinal tract. ${ }^{13}$

We cannot, therefore, offer a ready explanation for our observations. Caution must always be exercised in the interpretation of data derived from a 
small series of patients. However, a prospective study of tumour incidence in patients with PBC has now been established in the West of Scotland and other centres should also consider such a review.

\section{References}

${ }^{1}$ Miller DG. The association of immune disease and malignant lymphoma. Ann Intern Med 1967;66:507-21.

${ }^{2}$ Krasner N, Johnson PJ, Portmann B, Watkinson G, MacSween RNM, Williams R. Hepatocellular carcinoma in primary biliary cirrhosis: report of four cases. Gut 1979;20:255-8.

${ }^{3}$ Viteri A, Vernace SJ, Schaffner F. Extrahepatic malignancy in chronic liver disease: report of six cases. Gastroenterology 1976;71:1075-8.

${ }^{4}$ Chaput JC, Buffet C, Papoz L, Etienne JP. Chronic active hepatitis and extrahepatic malignancy. Lancet 1978; i: 1367 .

${ }^{5}$ Hill ID. Computing man years of risk. Br J Prev Soc Med 1972;26:132-4.

${ }^{6}$ Gillis CR, Boyle P, Hole DJ, Graham A. Scotland West Registry. In: Waterhouse JAH, Muir CS, Sham- mugaratnam $\mathrm{K}$, Powell $\mathrm{J}$, eds. Cancer incidence in five continents Vol IV. Lyon: IARC, 1981.

${ }^{7}$ Crowe J, Christensen E, Smith M, et al. Azathioprine in primary biliary cirrhosis: a preliminary report of an international trial. Gastroenterology 1980;78:1005-10.

${ }^{8}$ MacSween RNM, Scott AR. Hepatic cirrhosis: a clinicopathological review of 520 cases. J Clin Pathol 1973;26: 936-42.

${ }^{9}$ Penn I. Malignancies associated with immunosuppressive or cytotoxic therapy. Surgery 1978;83:492-502.

${ }^{10}$ Symington GR, MacKay IR, Lambert RP. Cancer and teratogenesis: infrequent occurrence after medical use of immunosuppressive drugs. Aust NZ J Med 1977;7: 368-72.

${ }^{11}$ Kinlen LJ, Eastwood JB, Kerr DNS, et al. Cancer in patients receiving dialysis. $\mathrm{Br}$ Med J 1980; :1401-3.

${ }^{12}$ Anonymous. Vitamin A and cancer. Lancet 1980;i:575-6.

${ }^{13}$ Wald N, Idle M, Boreham J, Bailey A. Low serum vitamin $A$ and subsequent risk of cancer: preliminary results of a prospective survey. Lancet 1980 ;ii:813-5.

Requests for reprints to: Dr PR Mills, Gastroenterology Unit, Royal Infirmary, Glasgow G4 OSF, Scotland. 